\title{
Early lung development and COPD
}

\section{Michael Silverman ${ }^{1}$ and Claudia E Kuehni ${ }^{2}$}

Commentary on: Poor airway function in early infancy and lung function by age 22 years: a non-selective longitudinal cohort study. Stern and co-authors, in this issue of the Lancet

\author{
Address for correspondence \\ Professor Michael Silverman \\ Department of Infection, Immunity \& Inflammation, University of Leicester \\ Robert Kilpatrick Clinical Sciences Building, \\ Leicester Royal Infirmary \\ PO Box 65, Leicester \\ LE2 7LX
}

Phone: 01162525881

Fax: 01162523282

E-mail: ms70@le.ac.uk

Full names, institution and country of all co-authors

1) The Leicester Children's Asthma Centre, Division of Child Health, Department of Infection, Immunity \& Inflammation, University of Leicester, Leicester, LE2 7LX, UK

2) Institute of Social and Preventive Medicine, University of Bern, CH - 3012 Bern, Switzerland

Word count text: 868 
To state that disturbed early development paves the way for later illness and accelerated senescence seems a truism. For pulmonary disease, this has been postulated for 30 years. ${ }^{1}$ Yet evidence to support this hypothesis is sparse. As recently as 2002, a major workshop on future directions in chronic obstructive pulmonary disease (COPD) failed to include early lung development in its future research agenda. ${ }^{2}$ Why has so little research been done?

The overwhelming evidence that cigarette smoking is the single biggest avoidable risk factor for adult lung diseases, both lung cancer and COPD, has dominated the research agenda for 50 years. Yet only a minority of smokers develops COPD, suggesting that it is the interaction between environmental exposures (such as tobacco smoke, air pollutants) and host factors (genetics, early lung growth, race, sex) that determines an individual smoker's susceptibility to COPD. ${ }^{3}$ While the role of genetics has been emphasised, ${ }^{4},{ }^{5}$ other host factors have been relatively neglected.

A limiting factor in this research is the huge logistic difficulty of studying the effect of exposures in fetal life or infancy on a disorder which only becomes apparent 50 - 60 years later. The journey from the uterus to senescence is long and eventful, with study participants surviving generations of researchers. Therefore research must rely on intermediate endpoints, biological events lying on the causal pathway between exposures and outcome. One such intermediate measure is lung function in early adulthood, which strongly predicts development of COPD. ${ }^{3,5}$ Joining together these links in the chain, the evidence for the importance of early life events as precursors of COPD is strengthened.

One such link is the report by Debra Stern and colleagues in today's Lancet. ${ }^{6}$ In a small but carefully nurtured cohort, the authors convincingly show that those individuals who had the lowest forced expiratory flows by the "squeeze" chest-compression technique (figure) as infants had poorer airway function by age 22 years. The association was not explained by current wheeze, atopy or smoking and persisted after bronchodilatation. These results are supported by data from other groups that show remarkable tracking of airway function from birth to middle childhood ${ }^{7,8}$ and from childhood to adulthood, ${ }^{9,10}$ although no study has so far has reached old age. The age of 22 years is important, because by then the lung has achieved maximum growth. Those with the poorest 
airway function at 22 years are likely to retain their low position in the lung function population and hence be the first to reach the threshold for the diagnosis of COPD $\left(\mathrm{FEV}_{1} / \mathrm{FVC}<70 \%\right)^{5}$

Stern and colleagues' report throws up several questions. First, what is the nature of the impairment in both neonatal and young-adult lung function? The assumption is that, in both age-groups, airway function (airway calibre or the elastic properties of the airway wall) is impaired. However, reduced pulmonary elastic recoil may also contribute to reduced flows. Therefore, the effect of air space development (alveolar or acinar) must also be considered. Abnormalities in this hidden region of the developing lung can influence forced flows and may contribute to the pathology of COPD, which includes airspace disease (emphysema) and airway abnormalities. Alveolar development occurs during the final 3 months of fetal life and the first 2-3 postnatal years, and is a prime target for many environmental exposures and pulmonary disorders at these ages. Until recently there has been no direct technique to study airspace development. New noninvasive methods that use the diffusion properties of stable noble gas isotopes such as helium-3, which can be detected by magnetic resonance, promise to provide a sensitive window on the acinus, ${ }^{11},{ }^{12}$ allowing the contribution of peripheral lung development on COPD to be studied.

Second, what are the fetal causes of impaired lung growth? Maternal cigarette smoking is the best recognised cause, with independent effects persisting into adult life. ${ }^{13}$ Stern and colleagues study might be too small to show this. More work is needed to identify other causes, both environmental (such as nutritional deficiency) and genetic. Such work would mean the collection of large prospective cohorts of newborn babies and doing lung-function tests in infants before postnatal exposures dominate. The ethical climate is changing and steadily moving against this sort of research, which makes Stern's study so important.

Finally, Stern and colleagues found that only $9-14 \%$ of the variability in spirometric lung function at age 22 years was explained by neonatal forced expiratory flows, leaving much room for other childhood exposures in the COPD pathway. Lower respiratory illness in young children, which Stern and others have shown to be strongly associated with neonatal airway function, may be an additional risk factor. Could preschool viral 
wheeze (formerly wheezy bronchitis) be a marker of later COPD? Chronic childhood asthma may contribute to adverse airway remodeling that tracks into adulthood. ${ }^{9}$ Outdoor air pollution affects growth in airway function. ${ }^{14}$ Worldwide, indoor air pollution from biomass cooking might be a greater environmental threat, but because it occurs in developing countries and exposure is mainly in women and young children, this topic has been largely ignored.

As COPD is set globally to become the third most important cause of death, now is the time to add research into its earliest origins to the agenda.

\section{References}

1. Burrows B, Knudson RJ, Lebowitz MD. The relationship of childhood respiratory illness to adult obstructive airway disease. Am Rev Respir Dis 1977;115:751-60.

2. Croxton TL, Weinmann GG, Senior RM, Hoidal JR. Future research directions in chronic obstructive pulmonary disease. Am J Respir Crit Care Med 2002;165:83844.

3. Chapman KR, Mannino DM, Soriano JB, et al. Epidemiology and costs of chronic obstructive pulmonary disease. Eur Respir J 2006;27:188-207.

4. Anto JM, Vermeire P, Vestbo J, Sunyer J. Epidemiology of chronic obstructive pulmonary disease. Eur Respir J 2001;17:982-94.

5. Calverley PM, Walker P. Chronic obstructive pulmonary disease. Lancet 2003;362:1053-61.

6. Stern D, Morgan W, Wright A, Guerra S, Martinez F. Poor airway function in early infancy and lung function by age 22 years: a non-selective longitudinal cohort study. Lancet 2007;370:in press.

7. Turner SW, Palmer LJ, Rye PJ, et al. The relationship between infant airway function, childhood airway responsiveness, and asthma. Am J Respir Crit Care Med 2004;169:921-7.

8. Wilson NM, Lamprill JR, Mak JC, Clarke JR, Bush A, Silverman M. Symptoms, lung function, and beta2-adrenoceptor polymorphisms in a birth cohort followed for 10 years. Pediatr Pulmonol 2004;38:75-81. 
9. Phelan PD, Robertson CF, Olinsky A. The Melbourne Asthma Study: 1964-1999. J Allergy Clin Immunol 2002;109:189-94.

10. Sears MR, Greene JM, Willan AR, et al. A longitudinal, population-based, cohort study of childhood asthma followed to adulthood. N Engl J Med 2003;349:1414-22.

11. Yablonskiy DA, Sukstanskii AL, Leawoods JC, et al. Quantitative in vivo assessment of lung microstructure at the alveolar level with hyperpolarized $3 \mathrm{He}$ diffusion MRI. Proc Natl Acad Sci U S A 2002;99:3111-6.

12. Waters B, Owers-Bradley J, Silverman M. Acinar structure in symptom-free adults by Helium-3 magnetic resonance. Am J Respir Crit Care Med 2006;173:847-51.

13. Upton MN, Smith GD, McConnachie A, Hart CL, Watt GC. Maternal and personal cigarette smoking synergize to increase airflow limitation in adults. Am J Respir Crit Care Med 2004;169:479-87. 